\title{
Fuzzy-PID-Based Control Algorithm Study
}

\author{
Yu Fan ${ }^{a}$, Wenhui Yang ${ }^{b^{*}}$ and Minghui Liu \\ School of computer science and engineering, Xi'an Technological University, Xi'an, Shaanxi 710021 \\ ayffshun@163.com, ${ }^{b} 1353678463 @ q q . c o m$ \\ *The corresponding author
}

\begin{abstract}
Keywords: Hyperthermia instrument; Flow control; Fuzzy PID control; Control precision; Parameter selection
\end{abstract}

\begin{abstract}
Reasonable parameters are the keys to ensure a system normal running and good operation, the simulation step response curve can verify the accuracy of the system parameters and the control quality of a system. As a combination of fuzzy control and PID control, Fuzzy PID control system involves many parameters, such as the fuzzy control related membership functions, quantization factor and scaling factor, PID control related proportional coefficient, integral coefficient and differential coefficient. This shows that the optimization and selection of above parameters can affects directly the stability and duration of response of PID control system. Therefore, to optimize and select these parameters is the key point of this topic.
\end{abstract}

\section{Introduction}

Fuzzy controller as the core components of the fuzzy control system, mainly impacts by the fuzzy control rules, membership functions to quantify the parameter, the scale factor and other factors. Therefore, setting the parameters of fuzzy control system is to ensure the good performance of the premise. Wherein the fuzzy control rules has a certain degree of certainty, based on human experience is established for the system which is more accurate and complex. so the fuzzy control rules which is established are generally not easy to change. The impact on the system, relative other parameters, is relatively small. Therefore, we only consider quantitative factors, scale factor which may greatly impact on the system parameters.

Three parameters of PID control, proportional coefficient $K_{P}$, integral coefficient $K_{I}$ and differential coefficient $\mathrm{K}_{\mathrm{D}}$, are major factors in determining the performance of PID controllers. That is, the quality of PID control system, directly dependent on the setting of these three parameters. In the PID control system modeling and simulation process, we need to adjust these three parameters to obtain better control effect. Through trial and error method to adjust the $\mathrm{K}_{\mathrm{P}}, \mathrm{K}_{\mathrm{I}}$ and $\mathrm{K}_{\mathrm{D}}$.

\section{Selection of System Parameters}

Quality of control system relies heavily on quantitative factors $\mathrm{Ke}, \mathrm{Kec}$ and the scale factor $\mathrm{Ku}$. However, different $\mathrm{Ke}, \mathrm{Kec}$ and $\mathrm{Ku}$ will produce different effects for system [1]. Generally, Ke, $\mathrm{Kec}$ and $\mathrm{Ku}$ can be a variety of combinations and different combinations may make the system get better control effect. Some process control system is very complex, we need to select different stages to different $\mathrm{Ke}, \mathrm{Kec}$ and $\mathrm{Ku}$, in order to ensure the system to get a good quality control.

If $\mathrm{Ke}$ and $\mathrm{Kec}$ are larger, system has higher control precision, this will make large errors in the case of the resolution becomes higher, thereby enabling the system overshoot and lead to a longer time to adjust the dynamic characteristics deteriorated. To make the system high control accuracy and shorter response time, we can increase $\mathrm{Ku}$. If you want to ensure that the system has a high degree of stability, you can be achieved by reducing the $\mathrm{Ku}$. Therefore, $\mathrm{Ke}, \mathrm{Kec}$ and $\mathrm{Ku}$, the basic principle of the adjustment is: If large or larger changes its deviation, in order to make the system response in the early stages, the two input variables of fuzzy controller can be in their theory good recognition within the maximum error, you need to $\mathrm{Ke}$ and $\mathrm{Kec}$ set to a smaller value. In this case, 
you want the system has a good dynamic and stability, you can choose a slightly bigger $\mathrm{Ku}$. If the deviation is small or the change is small, in other word, the system is closing to the steady state; you can try to choose $\mathrm{Ke}$ and $\mathrm{Kec}$ whichever is bigger, reducing the $\mathrm{Ku}$ way to reduce overshoot and reduces the response time of the system. Under normal circumstances, in the actual control system, we need to follow these principles at the same time, according to the specific project analysis and selection.

Fuzzy Control Preferences. For fuzzy control system, in the last chapter to choose a good fuzzy sets and fuzzy subset domain, this chapter mainly carries on the parameter choice and the simulation .According to the experience factor, scale factor and quantization features, four groups of selected parameters.

Group A parameters: quantization factor $\mathrm{Ke}=1 / 7, \mathrm{Kec}=1 / 8$, the scaling factor $\mathrm{Ku}=8$

Group B parameters: $\mathrm{Ke}=1 / 8, \mathrm{Kec}=1 / 4, \mathrm{Ku}=6$

Group C parameters: $\mathrm{Ke}=1 / 8, \mathrm{Kec}=1 / 4, \mathrm{Ku}=6$

Group D parameters: $\mathrm{Ke}=1 / 9, \mathrm{Kec}=1 / 6, \mathrm{Ku}=7$

Fuzzy control system simulation model for A set of parameters reached a steady state within 6.3s, the overshoot of $20 \%$. Obviously, the excessive overshoot of the system, and the transition process is too long; For group B parameters, the system reached a steady state within $5.5 \mathrm{~s}$, the overshoot of 14\%; For group C parameters for the system reached a steady within 5.6s, the overshoot of 13\%; For group D parameters for the system reached a steady within $5 \mathrm{~s}$, the overshoot of $11 \%$.

By analyzing the group $\mathrm{A}$, group $\mathrm{B}$, group $\mathrm{C}$ and group $\mathrm{D}$ parameters, continue to adjust the quantization factors and scaling factors to obtain a group which meeting the fuzzy control system requirementing for $\mathrm{Ke}, \mathrm{Kec}$ and $\mathrm{Ku}$ and Group $\mathrm{E}$ parameters: quantization factor $\mathrm{Ke}=0.1$, $\mathrm{Kec}=$ 0.2 , the scaling factor $\mathrm{Ku}=7$, a graph obtained by simulation step shown in Fig. 1. As it can be seen, after $4.9 \mathrm{~s}$, system reaches a steady state, the overshoot of $9 \%$.

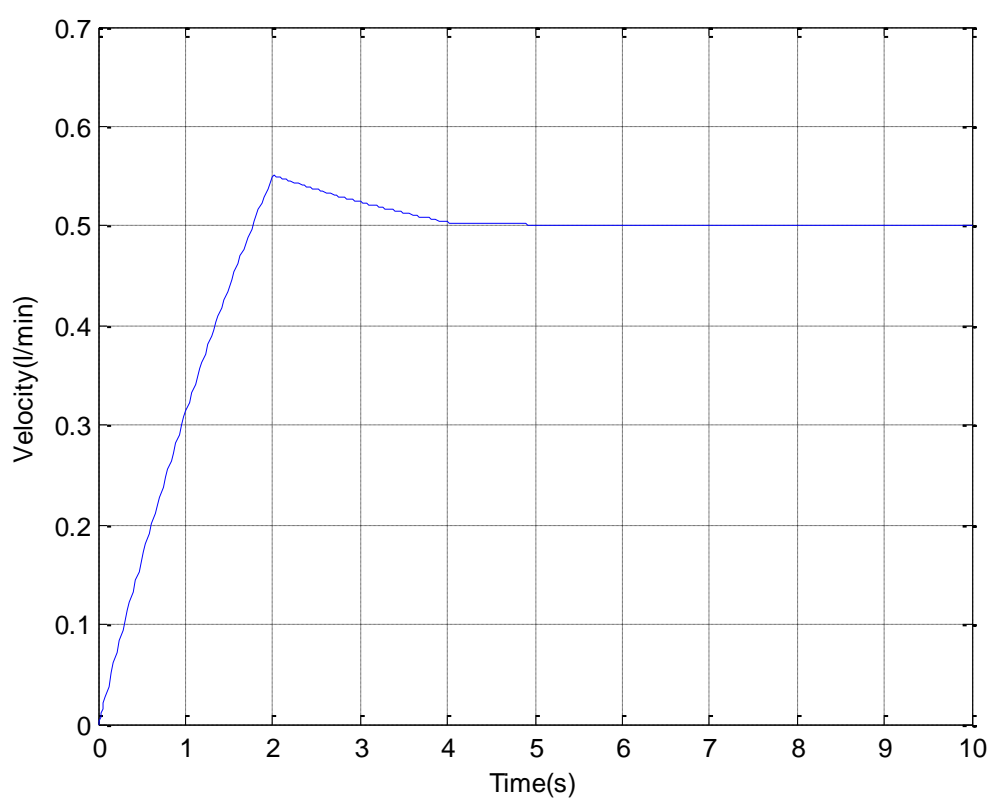

Figure 1. Step response curve of fuzzy control system

The comparative analysis of fuzzy control system step response curve of group A, B, C, D and E set of parameters to obtain the five sets of parameters overshoot responsing curves and time curves are shown in Fig. 2 and Fig. 3 . Abscissa from 1-5 represent the experimental group A group to five Group E parameters. As it can be seen from Fig. 2, the overshoot curve downward trend, and the smallest in Group E parameters. In Fig. 3, when using the E group, parameters response time is minimal. Thus, $\mathrm{E}$ is the best set of parameters. 


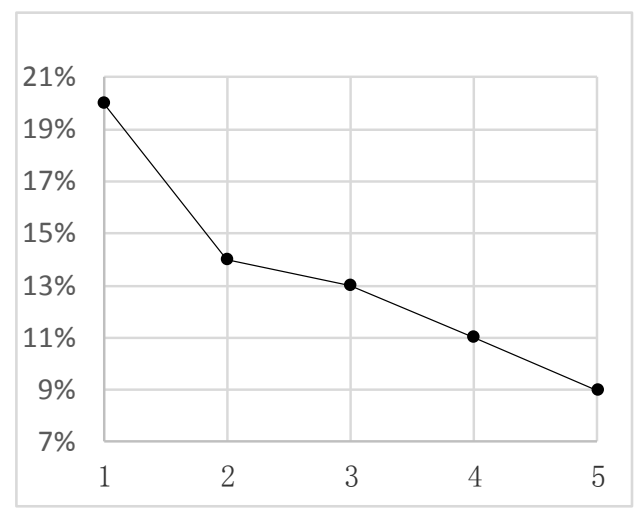

Figure 2. Experimental overshoot curve of fuzzy control parameters

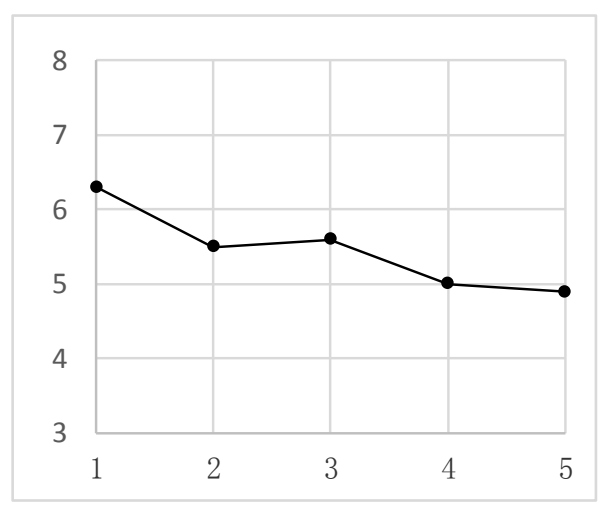

Figure 3. Fuzzy control parameter test response time curve

PID control parameters. Three parameters of PID control, proportional coefficient $K_{P}$, integral coefficient $\mathrm{K}_{\mathrm{I}}$ and differential coefficient $\mathrm{K}_{\mathrm{D}}$ is a major factor in determining the performance of PID controllers. In other word, the quality of PID control system directly dependen on the setting of these three parameters. In the PID control system modeling and simulation process, the need for the three parameters to be adjusted in order to obtain better control effect. Through trial and error method to adjust the $K_{P}, K_{I}$ and $K_{D}$.

Tuning PID control system parameters $K_{P}, K_{I}$ and $K_{D}$, get three sets of parameters

1) $\mathrm{KP}=15, \mathrm{KI}=18, \mathrm{KD}=0.7$

2) $\mathrm{KP}=10, \mathrm{KI}=25, \mathrm{KD}=1.5$

3) $\mathrm{KP}=12, \mathrm{KI}=21, \mathrm{KD}=1.7$

When setting velocity $\mathrm{V}=500 \mathrm{ml} / \mathrm{min}$, the above three sets of parameters into the PID control model, and then the PID control system step response curve obtained by simulation.

For parameter 1, the system reached a steady state within $4.4 \mathrm{~s}$, the overshoot of $28 \%$; For parameters 2 , the system reached a steady state within $3 \mathrm{~s}$, the overshoot of $22 \%$; for parameter 3 , system, after $3.3 \mathrm{~s}$,reaches a steady state, the overshoot of $16 \%$. It can be seen, these three groups of experimentally obtained results are not satisfactory, parameter 1 not only response time is too long, but also the overshoot is too large and poor system performance parameter. Parameter 2 although the response time of the system is reduced, but the overshoot is still great..Parameter 3, the response time than the parameter 1 decrease and overshoot becomes small, but stability is not good, not only the existence of a large steady-state error, but also overshoot is still a little high.

Use trial and error method adjusts repeatedly on three parameters $\mathrm{K}_{\mathrm{P}} \mathrm{K}_{\mathrm{I}}$ and $\mathrm{K}_{\mathrm{D}}$ tuning to obtain a set of system's demanding to meet the PID control parameters: $\mathrm{KP}=13, \mathrm{KI}=20, \mathrm{KD}=1.2$. The resulting step response curve shown in Fig. 4. As can be seen from Fig. 4, the system reaches a steady state after $3 \mathrm{~s}$ and the overshoot was $10.5 \%$. Comparing with the three experiments, the 
dynamic characteristics of the system not only is improved, but also the overshoot is lower .In general, the system can reach a steady state in a very short period of time, control is better.

The comparative analysis of the step response curves four parameters to obtain the four parameters curve of overshoot and the response time curve, as shown in Fig. 5 and 6, respectively. Abscissa from 1-4 represent the first group to the fourth group of four groups of experimental parameters. As can be seen from Fig. 5, the overshoot curve, the smallest in the fourth set of parameters. In Fig. 6, the using of a fourth set of parameters, the responding time is also minimal. It concluded that the fourth set of parameters is optimal.

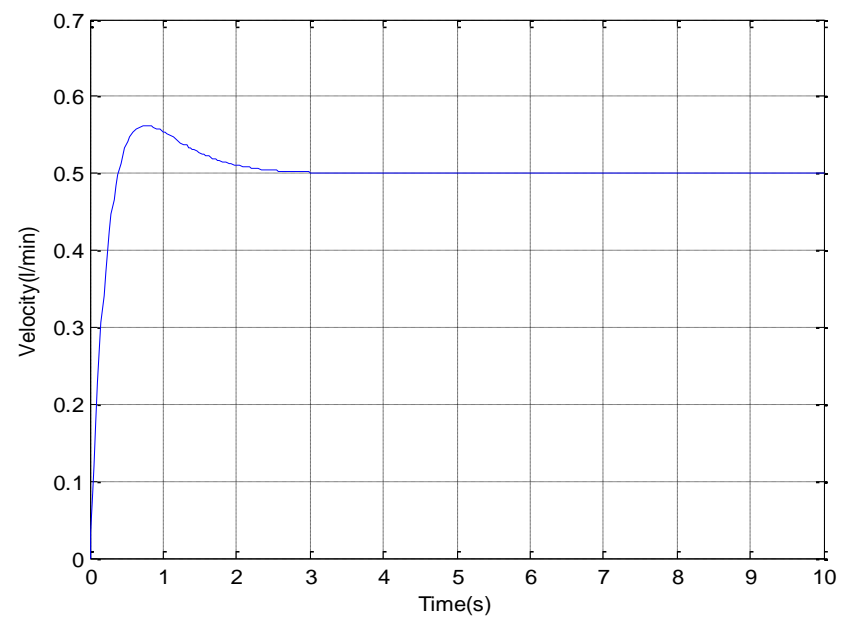

Figure 4. Step response curve of PID control system

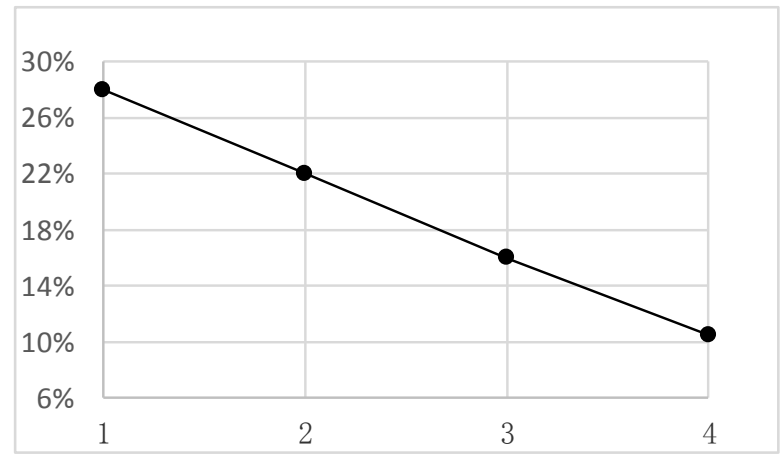

Figure 5. PID control parameters experimental curve overshoot

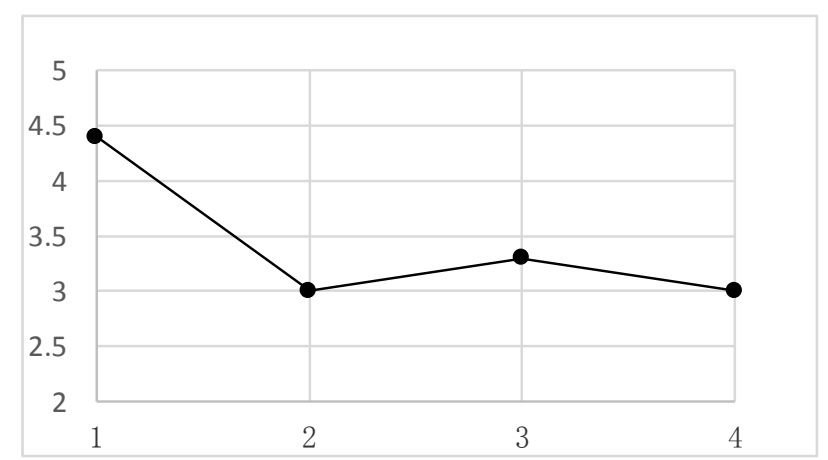

Figure 6. PID control parameter test response time curve 
Fuzzy PID Control of the Selection of Segmentation Points. Fuzzy control and PID control the selection of the segmentation points for quality control system is essential. If the error relative value is small, the choice of the fuzzy control, which makes the system steady-state error larger; Similarly, if the error relative value larger uses the PID control, resulting in slower response to the system, response process is longer and higher. Therefore, the fuzzy PID control system has better control performance, it is necessary to select the appropriate switching time [2][3].

According to the rule of fuzzy PID control, the selection of cutting points (error relative value is also known as the percentage) $\mathrm{m}$ is $10 \%$, that is: when the $\mathrm{m}>=10 \%$, the using of fuzzy control algorithm; when $\mathrm{m}<10 \%$, the using of PID control algorithm.

According to the fuzzy PID control law and the experiments prove that, the splitting point $\mathrm{m}$ which is $10 \%$ is the best, namely: when the $m>=10 \%$, using the fuzzy control algorithm, and at this time to ensure that the system has good dynamic characteristics and low overshoot quantity, and shorten the adjustment time of the system; when the $\mathrm{m}<10 \%$, using PID control algorithm, allowing the system to has a lower steady-state error and high control precision.

\section{Fuzzy PID Control System Simulation}

Setting the flow rate $\mathrm{V}=500 \mathrm{ml} / \mathrm{min}$, the fuzzy control and PID control get the best parameters used in the fuzzy PID control system model and simulation, get the step response curve as shown in Fig. 7. In Fig. 7, the system is stable and the overshoot is less than 3.5s. For the fuzzy PID control system, the method of fuzzy control and PID control can not only ensure the system has fast response speed, but also can reduce the overshoot and steady state error.

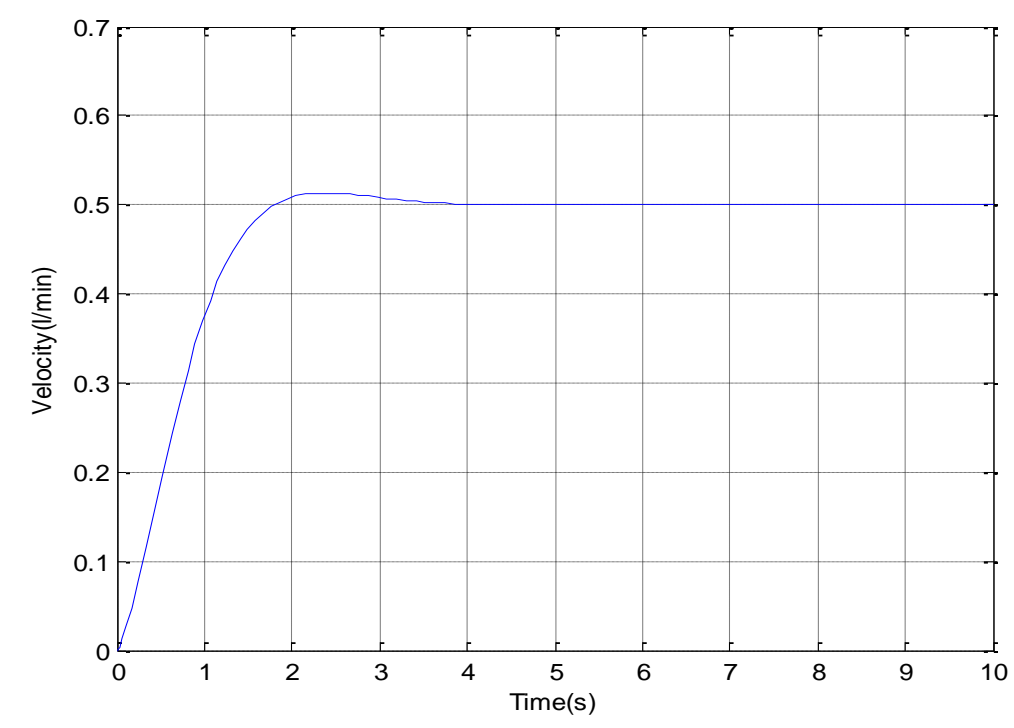

Figure 7. Step response curve of fuzzy PID control system

\section{Results Analysis}

Experimental results show that in hyperthermia instrument of velocity control in the process of adding fuzzy PID control algorithm. Respectively, the fuzzy control and PID control algorithm parameter selection, simulation was carried out and the optimal parameters were used in the model system. At the same time, according to choose the optimal cut-off point switch control algorithm, namely the relative error value is larger by fuzzy control, the error relative value is small by the PID control, the combination of the two, the realization of the advantages of fuzzy control and PID control algorithm which has better control effect. 


\section{References}

[1] Heising. Pole-restraining control for Modular Multilevel Converters in electric-ship applications. [J].2013, pp.11-13.

[2] Rasheed. Detection and study of various IR handheld remote control signals and using them for home applications. [M].Education and e-Learning Innovations (ICEELI), 2012 International Conference on, 2012, pp. 10-15.

[3] Maria G. loannides, "Design and Implementation of PLC-Based Monitoring Control System

[4] For Induction Motor," IEEE Transactions On Energy Conversion, VOL.19, NO.3, September 2004,pp. 469-476.

[5] Y. M. Jia, F. H. Su, J. Liu, "An On-line Insulation Monitoring System Based On Fieldbus", pp. 769-772.

[6] Chi Rong-hu. A new PI controller for freeway ramp metering based on fuzzy logic. [J].2013, pp. 46-76. 